\title{
Radiological versus Histopathological Diagnosis of Usual Interstitial Pneumonia in the Clinical Practice: Does It Have Any Survival Difference?
}

\author{
Silvia Quadrelli Luciana Molinari Lorena Ciallella Juan Carlos Spina \\ Edgardo Sobrino Julio Chertcoff
}

Buenos Aires British Hospital, Instituto de Investigaciones Médicas Alfredo Lanari, University of Buenos Aires, Buenos Aires, Argentina

\section{Key Words}

Usual interstitial pneumonia $\cdot$ High-resolution computed tomography $\cdot$ Histopathological prognosis

\begin{abstract}
Background: Recent studies have shown that quantification of specific histopathologic features found in usual interstitial pneumonia (UIP) are useful in defining a prognosis, suggesting the need of biopsy in all patients. Objectives: This study examines whether UIP-associated mortality is different in patients diagnosed by high-resolution computed tomography (HRCT) features considered definite of UIP and in patients with no definite radiological diagnosis that required histological confirmation of diagnoses. Methods: Forty-five patients were included (30 males, mean age $65.3 \pm 10.7$ years). Two groups of patients were identified: those with HRCT findings of definite UIP $(n=26)$ and those whose radiological diagnosis was not definite and required a surgical biopsy to confirm the presence of UIP $(n=19)$. Forced vital capacity, forced expiratory volume in $1 \mathrm{~s}$ and diffusing capacity for carbon monoxide were measured in all patients. All data were obtained from medical records, and the sur-
\end{abstract}

vival status was obtained by telephone or personal interview. All clinical parameters and HRCTs were obtained within 1 month before surgical lung biopsy. Results: Median survival was not different across groups and was similar to that previously reported (35 months). Kaplan-Meier analysis did not show any difference in 5 -year survival between both groups. Conclusions: In a clinical context in which the diagnosis of UIP can be obtained as a dynamic process that includes an integrated clinical, radiological and pathologic approach, a reliable diagnosis of UIP can be obtained based on a typical definite HRCT with no risk of including patients with a more benign disease and a more prolonged survival.

Copyright $\odot 2009$ S. Karger AG, Basel

\section{Introduction}

Idiopathic pulmonary fibrosis (IPF), also known as cryptogenic fibrosing alveolitis, is the most common form of idiopathic interstitial pneumonia (IIP) $[1,2]$. It is a chronic fibrosing interstitial lung disease (ILD) of unknown cause whose diagnosis carries a bleak prognosis. Although survival time varies considerably from patient

\section{KARGER}

Fax +41 613061234 E-Mail karger@karger.ch www.karger.com (c) 2009 S. Karger AG, Basel

0025-7931/10/0791-0032\$26.00/0

Accessible online at:

www.karger.com/res
Silvia Quadrelli

Combatiente de Malvinas 3150

Buenos Aires C1427ARO (Argentina)

Fax +54 1143043393

E-Mail silvia.quadrelli@gmail.com 
to patient, 5-year survival rates have been estimated at $30-50 \%$, although more recent data on patients, defined by the ATS/ERS criteria, indicate that median survival is only $2-3$ years $[3,4]$.

The diagnosis of IPF is best confirmed by the identification of usual interstitial pneumonia (UIP) on surgical lung biopsy. The UIP pattern is characterized by heterogeneity that includes patchy chronic inflammation (alveolitis), progressive injury (small aggregates of proliferating myofibroblasts and fibroblasts, termed 'fibroblastic foci') and fibrosis (dense collagen and honeycomb change) [5]. In the absence of a surgical lung biopsy, the diagnosis of IPF can be less certain. However, a diagnosis of IPF can be made with a high level of confidence for patients with distinct high-resolution computed tomography (HRCT) features of UIP, mainly fine and coarse inter- and intralobular septal thickening and honeycomb cyst formation with architectural distortion of the pulmonary parenchyma and associated traction bronchiectasis and bronchiolectasis.

Recent studies have shown that careful analysis and quantification of the specific histopathologic features found in UIP are useful in defining the prognosis of patients with IPF [6, 7]; on the other hand, some studies focused on the importance of the extent of interstitial fibrosis and cellularity on biopsy [8-10]. Additionally, some authors stress that CT findings are not specific enough to define prognosis, also pointing out the considerable interobserver variability that is seen in the clinical and radiologic diagnoses, even when performed by experts in the field $[11,12]$. This study examines whether UIP-associated mortality is different in patients diagnosed by HRCT features considered definite of UIP and in patients with no definite radiological diagnosis that required histological confirmation of diagnoses.

\section{Material and Methods}

The diagnosis of UIP was ascertained by typical radiographical findings or surgical lung biopsy demonstrating histological features of UIP. Patients with a history of drug toxicity, left ventricular failure or environmental exposures were excluded, but those with a defined connective tissue disease (CTD) were included. All patients, $18-75$ years of age, with a histological or radiological pattern typical of UIP at Buenos Aires British Hospital and Instituto de Investigaciones Médicas, University of Buenos Aires, from January 2000 to January 2007 were retrospectively included.

Biopsy slides were reviewed independently by 2 pathologists following published criteria [5]. Pathologists were blinded to clinical information. Patients were included as UIP only when both pathologists agreed on the histological diagnosis. HRCT was performed with 1.0 - or $1.5-\mathrm{mm}$-thick sections taken at 1 -cm intervals throughout the entire lung during inspiration in the supine position and through the caudal $10 \mathrm{~cm}$ of the lung at $2-\mathrm{cm}$ increments in the prone position [13]. One thoracic radiologist (J.C.S.) and 1 pulmologists (S.Q.), both of them experienced in ILDs, independently reviewed each HRCT scan. They were required to record each case as either definite or not definite UIP. The criteria used included those widely accepted as most consistent with UIP diagnoses: predominantly basal/subpleural distribution; a mixture of reticular and ground-glass abnormalities, with traction bronchiectasis when ground-glass attenuation was prominent; the absence of consolidation or nodules $[14,15]$. Patients were considered to have a definite CT diagnosis of UIP if the 2 observers agreed on the diagnosis. When disagreement was present, patients were referred to surgical biopsy.

Analyzed lung function measurements consisted of forced vital capacity (FVC), forced expiratory volume in $1 \mathrm{~s}\left(\mathrm{FEV}_{1}\right)$ and the diffusing capacity for carbon monoxide $\left(\mathrm{D}_{\mathrm{LCO}}\right)$ using a single breath technique (both measured using Sensor Medics Vmax 229, version ivs-0101-05-2). Results were expressed as percentages of predicted values [16].

All data were obtained from the medical records, and survival status was obtained by telephone interview and/or medical records. All the clinical parameters and the HRCTs were obtained within 1 month before surgical lung biopsy. The Medical Research Council (MRC) system was used for dyspnea scoring [17].

\section{Statistical Analysis}

All values were described as the mean \pm standard deviation, and the survival period was expressed as the mean \pm standard error. A $\chi^{2}$ statistics test or Fisher's exact test was used for categorical data, and an unpaired Student's t test was used for continuous data. Survival was evaluated using Kaplan-Meier survival curves and the log-rank test. Cox proportional hazards regression analysis was used to identify significant variables predicting survival status. A p value $<0.05$ was considered statistically significant (2-tailed). All data were analyzed using SPSS version 13.0 (SPSS, Inc., Chicago, Ill., USA).

This study was approved by the institutional review board of the Buenos Aires British Hospital.

\section{Results}

Forty-five patients were included ( 30 males, mean age $65.3 \pm 10.7$ years). At the time of the initial visit, the median time that patients experienced shortness of breath was $16.3 \pm 15.4$ months (range $0-53$ ). Baseline $\mathrm{FEV}_{1}$ was $76.4 \pm 21.5 \%$, FVC $70.8 \pm 16.1 \%, \mathrm{D}_{\mathrm{LCO}}$ adj $52.3 \pm 25.3 \%$ and $\mathrm{D}_{\mathrm{LCO}}$ /alveolar volume $91.54 \pm 35.64$. Pulse oxymetry showed a baseline resting oxygen saturation of $91.9 \pm$ $9.6 \%$.

Thirty-eight patients had IPF and 7 patients suffered CTD-associated UIP. Both groups of patients were similar concerning functional and clinical variables and the 
Fig. 1. Kaplan-Meier survival estimates.

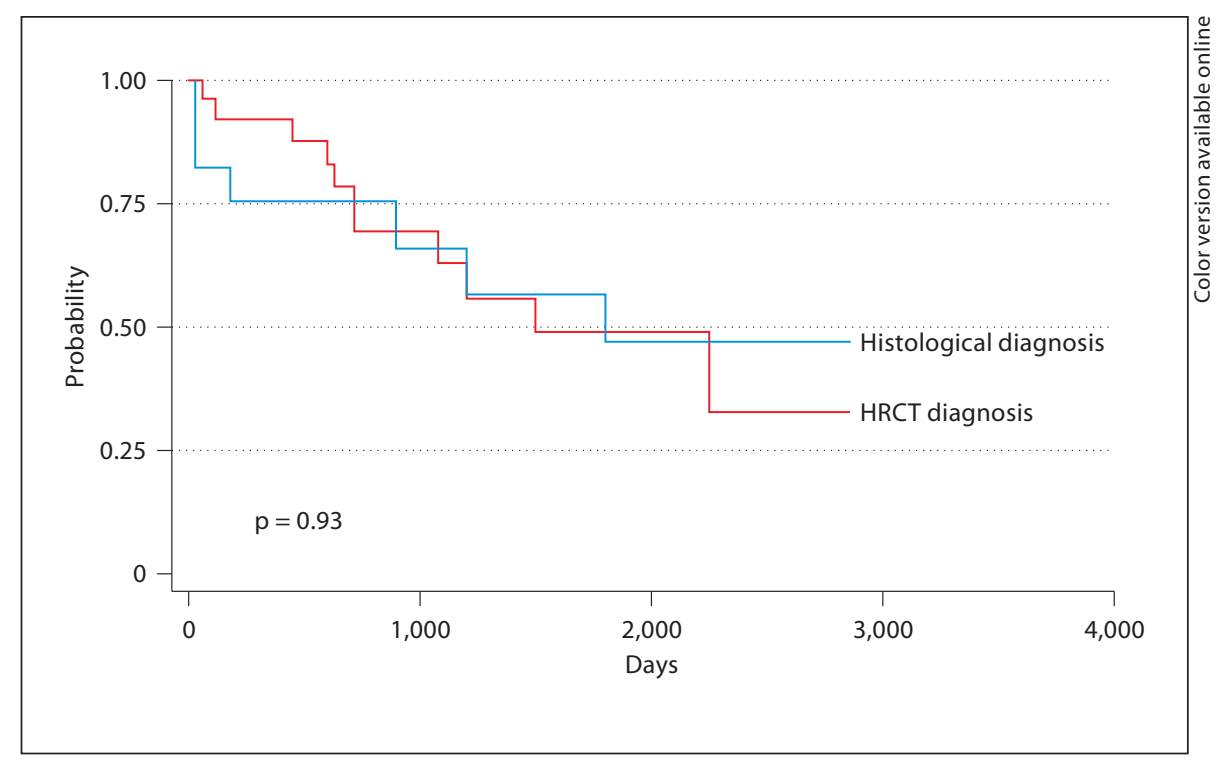

Table 1. Characteristics of the group with UIP associated with CTD versus IPF

\begin{tabular}{|c|c|c|c|}
\hline Characteristic & IPF & $\begin{array}{l}\text { UIP associated } \\
\text { with CTD }\end{array}$ & $\mathrm{p}$ \\
\hline Female sex, \% & 31 & 57 & 0.587 \\
\hline Age, years & $65.26 \pm 9.73$ & $64.14 \pm 16.89$ & 0.805 \\
\hline \multicolumn{4}{|l|}{ Diagnosed by surgical } \\
\hline biopsy & $0.58 \pm 0.50$ & $0.57 \pm 0.53$ & 0.971 \\
\hline $\mathrm{FEV}_{1}$, liters & $1.9258 \pm 0.63$ & $1.4933 \pm 0.28$ & 0.112 \\
\hline $\mathrm{FEV}_{1}, \%$ & $76.71 \pm 21.64$ & $71.33 \pm 24.58$ & 0.588 \\
\hline FVC, \% & $71.60 \pm 15.18$ & $63.67 \pm 23.66$ & 0.295 \\
\hline Ratio of $\mathrm{FEV}_{1}$ to FVC & $81.66 \pm 6.31$ & $80.91 \pm 10.29$ & 0.813 \\
\hline $\mathrm{D}_{\mathrm{LCO}}, \%$ & $54.22 \pm 25.10$ & $54.67 \pm 26.67$ & 0.969 \\
\hline $\mathrm{SO}_{2}, \%$ & $93.23 \pm 3.72$ & $86.67 \pm 18.97$ & 0.124 \\
\hline
\end{tabular}

Table 2. Characteristics of both groups

\begin{tabular}{|c|c|c|c|}
\hline Characteristic & $\begin{array}{l}\text { Radiological } \\
\text { diagnosis }\end{array}$ & $\begin{array}{l}\text { Histological } \\
\text { diagnosis }\end{array}$ & $\mathrm{p}$ \\
\hline Female sex, \% & 36.7 & 26.9 & 0.528 \\
\hline Age, years & $61.1 \pm 11.4$ & $68.3 \pm 9.2$ & 0.026 \\
\hline Times of dyspnea & $17.05 \pm 15.8$ & $14.92 \pm 15.2$ & 0.701 \\
\hline $\mathrm{FEV}_{1}, \%$ of predicted value & $68.42 \pm 22.48$ & $83.67 \pm 18.73$ & 0.056 \\
\hline FVC, $\%$ & $66.6 \pm 16.9$ & $72.9 \pm 15.6$ & 0.269 \\
\hline Ratio of $\mathrm{FEV}_{1}$ to FVC & $81.31 \pm 6.31$ & $81.78 \pm 7.70$ & 0.841 \\
\hline $\mathrm{D}_{\mathrm{LCO}}, \%$ & $55.7 \pm 18.8$ & $45.4 \pm 35.4$ & 0.302 \\
\hline $\mathrm{SO}_{2}, \%$ & $94 \pm 2.80$ & $87.6 \pm 16.4$ & 0.126 \\
\hline
\end{tabular}

percentage of patients diagnosed by surgical biopsy (table 1).

Two groups of patients were identified: those with HRCT findings of definite UIP $(n=26)$ and those whose radiological diagnosis was not definite and required a surgical biopsy to confirm the presence of UIP $(n=19)$. In the 26 patients who had a radiological picture which was felt to represent definite UIP, histological diagnosis was not confirmed. Patients with radiological definite UIP were slightly younger than those without definite diagnoses $(61.1 \pm 11.4$ vs. $68.3 \pm 9.2$ years; $p=0.026)$. Both groups were similar in sex (females 36.7 vs. $26.9 \%$; $\mathrm{p}=0.5283)$, proportion of patients with very mild dyspnea (MRC I 5.26 vs. $11.5 \%$; $\mathrm{p}=1.000$ ) and duration of symptoms at the time of diagnosis $(17.05 \pm 15.89$ vs. $14.92 \pm 15.20$ months; $p=0.701)$. Functional impairment was not significantly different (table 2). Median survival was not different $(35.10 \pm 25.72$ vs. $39.7 \pm 44.90$ months; $\mathrm{p}=0.671)$. The overall 5 -year survival rate of patients with histological and radiological diagnosis of UIP was 51.2 and $42.8 \%$, respectively (fig. 1). No significant differences in the overall survival (adjusted by age) were found between the 2 groups ( $\mathrm{p}=0.138$ ).

When only the group of 38 patients with IPF was analyzed, overall survival (adjusted by age) was not different in patients with histological and radiological diagnosis of UIP (5-year survival 45.4 vs. $34.6 \%$; $\mathrm{p}=0.799$ ). 


\section{Discussion}

UIP is a distinct histological pattern observed in IPF $[3,5]$ but is also found in other clinical entities (e.g., collagen vascular diseases - CVD, asbestosis, diverse occupational, environmental or drug exposures) $[18,19]$. UIP is the most common pattern of IIP, seen in $47-62 \%$ of recent series compared with 14-36\% for nonspecific interstitial pneumonia (NSIP) [20-22], with similar results at our own institution [23]. Although it has been shown that the prognosis of collagen vascular disease/UIP was better than that of IPF/UIP without lead time bias [24, 25], in the decision-making process for treatment and prognosis, the most important selection is to define if an interstitial pneumonia is a UIP or not. UIP progresses inexorably over months to years, with progressive fibrosis and destruction of lung parenchyma $[3,26]$; spontaneous remissions do not occur. Therefore, most patients die of respiratory failure, with a mean survival of 2.8-3.6 years $[20-22,27,28]$. That differs markedly from the NSIP survival, a difference that remains whatever the origin of UIP or NSIP.

A definitive diagnosis of UIP requires surgical lung biopsy $[3,5]$, but the diagnosis of UIP can be affirmed with confidence by HRCT scans in some patients $[15,29$, 30].

In designing this study, we aimed to reproduce the application of current recommendations for the routine diagnostic evaluation of diffuse lung disease in the clinical practice. Current consensus suggests that the diagnosis of UIP can be accepted if findings in the HRCT scan are judged as definite UIP by at least 2 experienced observers. Patient characteristics in our series were typical of populations with fibrotic IIP managed in a referral center only with clinical purposes. Two expert radiologic evaluations distinguishing between UIP and NSIP on HRCT are not always available in routine clinical practice. The real clinical scenario is the agreement of 1 radiologist and 1 pulmonologist experienced in ILD evaluation. In that context, $42 \%$ of our patients with a final diagnosis of UIP required a surgical biopsy in order to arrive at that diagnosis. Patients whose diagnoses were made by HRCT or by histological confirmation did not show any difference in survival. Median survival was not different between the groups and was similar to that previously reported (35 months) [4].

The accuracy of a clinical diagnosis of IPF and other ILDs was assessed by Raghu and colleagues [31] in a prospective study of 59 consecutive patients who were referred to a tertiary medical center with recognized exper- tise in the management of ILDs. In that study, ILD diagnosis was performed by a senior ILD specialist, a senior chest radiologist who evaluated chest radiographs and HRCTs independently and with 2 separate biopsy specimens that were obtained from the same lung, and evaluated by a senior pulmonary pathologist who was familiar with the classification and characteristic histopathologic features of the various ILDs. In those conditions (only obtainable in a clinical setting of a referral hospital with experience in ILD), the specificity of clinical diagnosis was $97 \%$ and the radiological diagnosis $90 \%$. Hunninghake and colleagues [15] conducted a prospective analysis of 91 patients suspected of having IPF. They showed that when lower lobe honeycombing and upper lung irregular lines were present, the IPF diagnosis could be made with a specificity of $81 \%$ and a positive predictive value of $85 \%$. The problem they stressed is that the agreement on a specific diagnosis of the whole cohort was roughly $50 \%$. For this study, we selected only those patients about whom a full agreement was met by the 2 observers (radiologist and pulmonologist) and on clinical and radiological basis. We hypothesized that if a diagnosis based on those 2 accepted methods resulted in a similar survival, it would add to relying on a certain and consensus-based radiological diagnosis of UIP without requiring histological confirmation. Research conditions (like a histological confirmation in patients with a certain diagnosis of UIP) which are used in most experimental contexts for prospective studies are not necessarily recommended for the routine clinical practice.

In the study by Flaherty and colleagues [25] who evaluated HRCT scans from 73 patients with a histopathologic diagnosis of UIP/IPF and from 23 patients with a histopathologic diagnosis of NSIP, $36 \%$ with a histopathologic diagnosis of UIP were given diagnoses of NSIP based on HRCT. Interestingly, their findings differ from our results, as among patients with histopathologic UIP, the typical HRCT presentation, which leads to a radiologic diagnosis of definite or probable UIP, was associated with poorer median survival than atypical HRCT presentation ( 2.1 vs. 5.8 years; $p=0.04$ ) [32], while in our patients with histological diagnosis of UIP but atypical HRCT findings, survival was not different. However, Sumikawa et al. [33] have recently shown that in their patients who had biopsy-proven IPF with an UIP pattern on the biopsy, the pattern of abnormality on thin-section CT, whether characteristic of UIP or not, did not influence prognosis.

Some variables with potential impact on survival were not controlled in our study (neither in the Flaherty or 
Sumikawa patients), such as the extent of HRCT involvement $[34,35]$ or functional impairment $[36,37]$. Additionally, we included 7 CTD patients, but none of them with systemic sclerosis. We chose to include CTD patients because in daily practice, the usual clinical dilem$\mathrm{ma}$ is the same as in suspected IPF, i.e. whether pulmonary involvement corresponds to a UIP pattern or not. Differences in inclusion criteria or underrecognized differences in functional impairment or extent of disease may have resulted in different sample composition among patients without typical HRCT findings concerning factors with an influence on survival and explain the different results in both studies.

However, from a practical point of view, the important conclusion is that if patients really have a definite diagnosis of UIP in HRCT, the survival is not different from the survival seen in patients with histological confirmation. Anyway, current recommendations suggest that in the absence of typical findings, patients should receive a surgical biopsy. On the other hand, the potential risk of accepting a radiological diagnosis of UIP is to anticipate wrongly a very poor prognosis and extremely low expectancy of response to treatment, which usually endorses a very limited intent of treatment. We believe that we have provided data derived from a typical clinical sample, showing that the method of diagnosis (typical definite HRCT findings of UIP vs. histological confirmation) does not influence survival.

In a clinical context in which the diagnosis of UIP can be obtained as a dynamic process that includes an integrated clinical, radiological and pathologic approach, a reliable diagnosis of UIP can be obtained based on a typical definite HRCT with no risk of including patients with a more benign disease and the hope of a more prolonged survival.

\section{References}

1 Demedts M, Wells AU, Anto JM, Costabel U, Hubbard R, Cullinan P, Slabbynck H, Rizzato G, Poletti V, Verbeken EK, Thomeer MJ, Kokkarinen J, Dalphin JC, Taylor AN: Interstitial lung diseases: an epidemiological overview. Eur Respir J Suppl 2001;32:2s$16 \mathrm{~s}$.

-2 Thomeer MJ, Costabel U, Rizzato G, Poletti V, Demedts M: Comparison of registries of interstitial lung diseases in three European countries. Eur Respir J Suppl 2001;32:114s$118 \mathrm{~s}$.

$\checkmark 3$ American Thoracic Society: Idiopathic pulmonary fibrosis: diagnosis and treatment. International consensus statement. American Thoracic Society (ATS), and the European Respiratory Society (ERS). Am J Respir Crit Care Med 2000;161:646-664.

4 King TE Jr, Tooze JA, Schwarz MI, Brown KR, Cherniack RM: Predicting survival in idiopathic pulmonary fibrosis: scoring system and survival model. Am J Respir Crit Care Med 2001;164:1171-1181.

$\checkmark 5$ Katzenstein AL, Myers J: Idiopathic pulmonary fibrosis: clinical relevance of pathological classification. Am J Respir Crit Care Med 1998;157:1301-1315.

-6 King TE Jr, Schwarz MI, Brown K, Tooze JA, Colby TV, Waldron JA Jr, Flint A, Thurlbeck W, Cherniack RM: Idiopathic pulmonary fibrosis: relationship between histopathologic features and mortality. Am J Respir Crit Care Med 2001;164:1025-1032.

7 Lynch DA: Imaging of diffuse infiltrative lung disease. Eur Respir Mon 2000;14:2954 .
-8 Selman M, King TE Jr, Pardo A: Idiopathic pulmonary fibrosis: prevailing and evolving hypotheses about its pathogenesis and implications for therapy. Ann Intern Med 2001; 134:136-151.

-9 Bjoraker JA, Ryu JH, Edwin MK, Myers JL, Tazelaar HD, Schroeder DR, Offord KP: Prognostic significance of histopathologic subsets in idiopathic pulmonary fibrosis. Am J Respir Crit Care Med 1998;157:199_ 203.

-10 Schwartz DA, Helmers RA, Galvin JR, Van Fossen DS, Frees KL, Dayton C, Burmeister LF, Hunninghake GW: Determinants of survival in idiopathic pulmonary fibrosis. Am J Respir Crit Care Med 1994;149:450-454.

-11 Peckham RM, Shorr AF, Helman DL Jr: Potential limitations of clinical criteria for the diagnosis of idiopathic pulmonary fibrosis/ cryptogenic fibrosing alveolitis. Respiration 2004;71:165-169.

12 Aziz ZA, Wells AU, Hansell DM, Bain GA, Copley SJ, Desai SR, Ellis SM, Gleeson FV, Grubnic S, Nicholson AG, Padley SP, Pointon KS, Reynolds JH, Robertson RJ, Rubens MB: HRCT diagnosis of diffuse parenchymal lung disease: interobserver variation. Thorax 2004;59:506-511.

13 Kazerooni EA, Martinez FJ, Flint A, Jamadar DA, Gross BH, Spizarny DL, Cascade PN, Whyte RI, Lynch JP 3rd, Toews G: Thin-section CT obtained at $10-\mathrm{mm}$ increments versus limited three-level thin-section CT for idiopathic pulmonary fibrosis: correlation with pathologic scoring. AJR Am J Roentgenol 1997;169:977-983.
14 MacDonald SL, Rubens MB, Hansell DM, Copley SJ, Desai SR, du Bois RM, Nicholson AG, Colby TV, Wells AU: Nonspecific interstitial pneumonia and usual interstitial pneumonia: comparative appearances and diagnostic accuracy of high-resolution computed tomography. Radiology 2001;221: 600-605.

-15 Hunninghake GW, Lynch DA, Galvin JR, Gross BH, Müller N, Schwartz DA, King TE Jr, Lynch JP 3rd, Hegele R, Waldron J, Colby TV, Hogg JC: Radiologic findings are strongly associated with a pathologic diagnosis of usual interstitial pneumonia. Chest 2003; 124:1215-1223

16 Quadrelli S, Bosio M, Salvado A, Chertcoff J: Valor de la espirometria para el diagnostico de restricción pulmonar. Medicina 2007;67: 685-690.

17 Fletcher CM: Standardized questionnaire on respiratory symptoms: a statement prepared and approved by the MRC Committee on the Aetiology of Chronic Bronchitis (MRC breathlessness score). BMJ 1960;2:1665.

18 American Thoracic Society/European Respiratory Society International Multidisciplinary Consensus Classification of the Idiopathic Interstitial Pneumonias. Am J Respir Crit Care Med 2002;165:277-304.

19 Lynch JP III, Orens J, Kazerooni EA: Collagen vascular diseases; in Sperber M (ed): Diffuse Lung Diseases: A Comprehensive Clinical-Radiological Overview. London, Springer, 1999. 
20 Travis WD, Matsui K, Moss J, Ferrans VJ: Idiopathic nonspecific interstitial pneumonia: prognostic significance of cellular and fibrosing patterns: survival comparison with usual interstitial pneumonia and desquamative interstitial pneumonia. Am J Surg Pathol 2000;24:19-33.

-21 Nagai S, Kitaichi M, Itoh H, Nishimura K Izumi T, Colby T: Idiopathic nonspecific interstitial pneumonia/fibrosis: comparison with idiopathic pulmonary fibrosis and BOOP. Eur Respir J 1998;12:1010-1019.

-22 Bjoraker JA, Ryu JH, Edwin MK, Myers JL, Tazelaar HD, Schroeder DR, Offord KP: Prognostic significance of histopathologic subsets in idiopathic pulmonary fibrosis. Am J Respir Crit Care Med 1998;157:199203.

-23 Quadrelli S, Lyons G, Ciallella L, Iotti A, Chertcoff J: Biopsia en enfermedad intersticial pulmonar. Medicina 2007;67:691-697.

24 Park JH, Kim DS, Park IN, Jang SJ, Kitaichi M, Nicholson AG, Colby TV: Prognosis of fibrotic interstitial pneumonia: idiopathic versus collagen vascular disease-related subtypes. Am J Respir Crit Care Med 2007;175: 705-711.

-25 Flaherty KR, Colby TV, Travis WD, Toews GB, Mumford J, Murray S, Thannickal VJ, Kazerooni EA, Gross BH, Lynch JP III, Martinez FJ: Fibroblastic foci in usual interstitial pneumonia: idiopathic versus collagen vascular disease. Am J Respir Crit Care Med 2003;167:1410-1415.

-26 Tukiainen P, Taskinen E, Holsti P, Korhola O, Valle M: Prognosis of cryptogenic fibrosing alveolitis. Thorax 1983;38:349-355.
27 Gay SE, Kazerooni EA, Toews GB, Lynch JP 3rd, Gross BH, Cascade PN, Spizarny DL, Flint A, Schork MA, Whyte RI, Popovich J, Hyzy R, Martinez FJ: Idiopathic pulmonary fibrosis: predicting response to therapy and survival. Am J Respir Crit Care Med 1998; 157:1063-1072.

28 Riha ARL, Duhig EE, Clarke BE, Steele RH, Slaughter RE, Zimmerman PV: Survival of patients with biopsy-proven usual interstitial pneumonia and nonspecific interstitial pneumonia. Eur Respir J 2002;19:11141118.

29 Hunninghake GW, Zimmerman MB, Schwartz DA, King TE Jr, Lynch J, Hegele R, Waldron J, Colby T, Müller N, Lynch D, Galvin J, Gross B, Hogg J, Toews G, Helmers R, Cooper JA Jr, Baughman R, Strange C, Millard M: Utility of a lung biopsy for the diagnosis of idiopathic pulmonary fibrosis. Am J Respir Crit Care Med 2001;164:193-196.

30 Diette GB, Scatarige JC, Haponik EF, Merriman B, Fishman EK: Do high-resolution CT findings of usual interstitial pneumonitis obviate lung biopsy? Respiration 2005;72: 134-141.

-31 Raghu G, Mageto YN, Lockhart D, Schmidt RA, Wood DE, Godwin JD: The accuracy of the clinical diagnosis of new-onset idiopathic pulmonary fibrosis and other interstitial lung disease. Chest 1999;116:1168-1174.

32 Flaherty KR, Thwaite EL, Kazerooni EA, Gross BH, Toews GB, Colby TV, Travis WD, Mumford JA, Murray S, Flint A, Lynch JP 3rd, Martinez FJ: Radiological versus histopathological diagnosis in UIP and NSIP: survival implications. Thorax 2003;58:143148.
33 Sumikawa H, Johkoh T, Colby TV, Ichikado K, Suga M, Taniguchi H, Kondoh Y, Ogura T, Arakawa H, Fujimoto K, Inoue A, Mihara $\mathrm{N}$, Honda O, Tomiyama N, Nakamura H, Muller NL: Computed tomography findings in pathological usual interstitial pneumonia: relationship to survival. Am J Respir Crit Care Med 2008;177:367-368. DOl 10.1164/ rccm.200611-1696OC.

34 Wells AU, King AD, Rubens MB, Cramer D, du Bois RM, Hansell DM: Lone cryptogenic fibrosing alveolitis: a functional-morphologic correlation based on extent of disease on thin-section computed tomography. Am J Respir Crit Care Med 1997;155:1367-1375.

35 Nagao T, Nagai S, Hiramoto Y, Hamada K, Shigematsu M, Hayashi M, Izumi T, Mishima M: Serial evaluation of high-resolution computed tomography findings in patients with idiopathic pulmonary fibrosis in usual interstitial pneumonia. Respiration 2002;69: 413-419.

36 Hallstrand TS, Boitano LJ, Johnson WC, Spada CA, Hayes JG, Raghu G: The timed walk test as a measure of severity and survival in idiopathic pulmonary fibrosis. Eur Respir J 2005;25:96-103.

37 Latsi PI, du Bois RM, Nicholson AG, Colby TV, Bisirtzoglou D, Nikolakopoulou A, Veeraraghavan S, Hansell DM, Wells AU: Fibrotic idiopathic interstitial pneumonia: the prognostic value of longitudinal functional trends. Am J Respir Crit Care Med 2003;168: 531-537. 